\title{
Desire Lines: determining pathways through the city
}

\author{
A. Furman \\ School of Interior Design, Faculty of Communication and Design, \\ Ryerson University, Canada
}

\begin{abstract}
The paper focuses on North American current situations concerned with Walkability, a term that refers to the level of amenity that an area provides a person with the many pleasant and interconnected experiences dealing with movement.

Questions are raised as to why in the built-up portions of the city, the realization of Desire Lines are slow to emerge? Where is the permeability a city offers for walking based on Desire Lines? This term, coined by French Philosopher Gaston Bachelard, refers to the psychological, physical need to get from one place to the next, 'les chemins du désir.' We need to add to the general discussions about the quality of our sidewalk and park spaces, important edge conditions that have been exhaustively studied in theory and practice and grapple with the conditions found at the street level where the sidewalk and property line meets a wall of impermeability. The level of amenity that such built-up urban areas could provide to pedestrians as additional permeable walking space, it is argued, needs more attention by planners, architects, and designers to fully serve the needs of pedestrians that defines the urban experience.

Keywords: pedestrianism, walkability, sojourn, permeability, path, pathways, public realm, urban filaments, Desire Lines, short cut, tactics.
\end{abstract}

\section{Short cut}

To walk is to lack a place. M. de Certeau

Our hero in this opening sequence has to enter and emerge at the other end of this urban object, a massive, solid form, architecturally rendered with the latest glass technology and pocked with metal-framed plate glass apertures. Our hero 
feels the pressure of the internal conditioned air as the hinged door succumbs (albeit temporarily) into its guise as a traditional threshold. It doesn't like being pulled and turned into this role as part of an all-too-human-centered space; it prefers rather, the pleasing effect of being a part of the larger whole - the blank face of the streetscape, reflective, mute and pure. Our hero pushes on

Taking a short cut through an urban mall is a messy dance, especially for those not attuned to the artfulness of the modern flâneur and flâneuse who glide through such spaces in distracted bemusement while engaged in conversation or in mid-communication on their cellphone-PDA; no simple pattern emerges in the layout, which has a tendency to change every few weeks-the urban sojourner has no choice but to pass many displays of objects artfully arranged along a path strewn with an archipelago of merchandise and signs. It is interesting that there is an actual interior design science to arranging obstacles (often down the center of a very wide aisle) to slow traffic to a crawl in these modern arcades - these overly wide descendants of the original glass-encrusted spindly-arcaded passages from the early 1800 s in Paris and London.

One crosses the many columned grids, is diverted off-course, eyes seeking down a corridor looking for a cardinal point, and reconnects onto the original interior path in order to find sanctuary, which is the goal, the imaginary 'point B' from the starting point. The modern large interior space is no longer on the same ground level as the street, or only just one level above the street as the original arcades were (at times used for various shops and programs on upper levels). The modern large commercial space pulls visitors up by chain-powered step, down, and interconnects multiple levels with natural light wells and scenographic lighting displays-all reflections, multiple shadows cast and point sources of light scattering any one center into many private centers. Adam Gopnik suggests that the hot summers bring in, more often, the perambulator into the acclimatized air but the winter city defeats the real enemy of the city the car, because one can endure the cold better, and therefore one can choose to remain outdoors than the heat with proper clothing [4, p. 193].

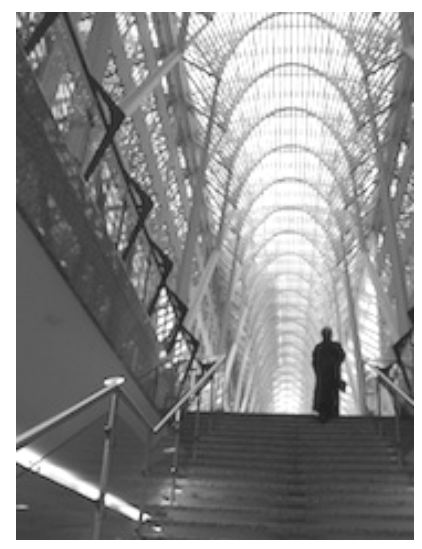

Figure 1: Santiago Calatrava's Galleria, an Urban Filament, Toronto's PATH. 
Seeking sanctuary, for whatever reason, one might ask while in such a modern space of enclosure-where is the juncture between and through the enclosed spaces and buildings that define the urban experience? And is this experience a different but altogether satisfying experience controlled by the perambulator?

This paper questions the role short cuts play in the experience of walking in the built-up portions of the many North American cities whose dominant street pattern is one of a largely solid wall of buildings abutting the sidewalk.

Walkability is the level of amenity an area provides a person with many pleasant and interconnected experiences dealing with movement. The city experience ought to be much richer, it is argued, in these built-up areas because of their diversity and intensity of building program, etc., than in the edge conditions of sidewalks and open spaces. Each space has its own value and this paper is an introduction to how the existing built-up spaces need the same consideration and aesthetic experience that is, ultimately a public situation - that is, paradoxically, a social, personal event that is contemplative in nature.

\section{Of maps, old and new}

The contemporary large North American city has no longer any clear beginning or ending, it drifts and blurs and extends. Traditional drawings of these areas are now liquid, scaleless; they naturally hand over their historic authority to the GPS equipped cellular phone in order to track and seek out points with quasispecificity. In such a system the role of the Urban Filament, a form of spaces supportive to streets but not necessarily part of the main motorized vehicular circulation system of a city, are invisible. They exist as unique paths that amplify pedestrian and cyclist opportunity in urban areas not always evident in maps and from the street, since they exist in and around buildings, including private properties. There are three general types of urban filaments considered to exist or an emerging pattern to be found in the built-up city: the interior eventspace, public interiors, and ribbons. [3, p. 270-2].

The contemporary (paper) map-user, or on-line Google earth-user seeks out new possible sites to explore that would benefit from more choice, more pathways, and more experiences in the city. Interestingly, however, the real test of being able to identify such a system overlaid onto the aerial map is the traditional ground-level exploration using eyes and walking as an experience when locating possible sites for Urban Filaments. The relatively recent acceptance of the 'Google street view' software does manage to bridge the map with the phenomenological experience of walking, yet it does not help when understanding space at a nuanced level, which tends to reveal less about the realness of space (tactile and multiple senses used). Denis Wood, in The Power of Maps explores how almost all detail, subtlety and nuance is missing in most maps [11, p. 71]. The knowledge from on-line sources needs to be expanded to reflect actual experienced qualities found in the knowledge acquired by footfall.

Sheller and Urry argue for in depth studies that look at how cars have created a western culture of 'automobility' where the car is representative of all the 
'convenience devices of contemporary society, devices that make complex, harried patterns of social life, especially in the city, just about possible.' $[10, \mathrm{p}$. 744] and because of the neediness of the car for space, pedestrians and cyclists are the users of only a 'small sliver' of the leftover public (and publiclyaccessible) private space in the city [10, p. 754].

\section{Desire Lines + Urban Filaments}

Urban Filaments [3, p. 270] fundamentally are spaces that are tactical in nature, and do not subscribe to the extant urban street pattern in order to generate their shape - they aren't controlled by the street grid concept of intersections designed mainly for motor vehicle travel where the dominant idea is an uninterrupted visual axis, uncluttered by obstacles, basically the ideal path of a cannon down a Boulevard or automobile in a (constant) high gear.

Urban Filaments, the physical representations of Desire Lines in the built-up city are selectively chosen; just as dense forests retain their true purpose when they are selectively harvested for lumber and timber rather than simply clear-cut, the Urban Filament may be hidden from view and at other times it might be part of a visible open public field.

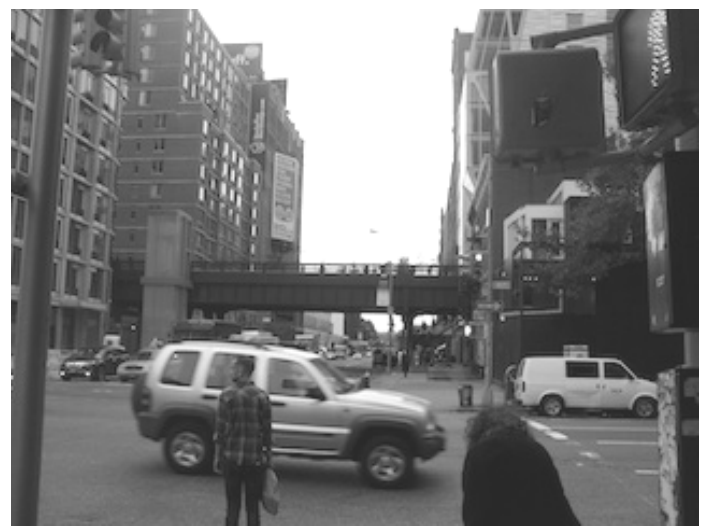

Figure 2: An Urban Filament/Desire Line: The Highline park, New York.

The Urban Filament, in its raw conceptual form is the equivalent to the core drill or tapping infrastructure of the offshore oilrigs; the desire to reach a destination (below the sea bed or across a highway/beyond a party wall in a dense urban street) is the start of the exploration. Like the oilrig, the path isn't a straight line, it is subject to the whims of the unnatural system that bends and folds it as it becomes actualized in the system of the extant street grid(s).

The pedestrian desire to move is somewhat predictable in that they will, like motorized vehicles, go to where there are less interruptions to their path of travel, (as epitomized in Jan Gehl's studies of pedestrian preference for softly rising ramps versus stairs) and where it is more convenient, meaning a shorter distance from $\mathrm{a}$ to $\mathrm{b}$, whenever possible. Desire Lines/Urban Filaments intermingle 
private and public spaces, and by association there is an intermingling of commercial and 'free' activity. Thresholds become blurred; edges indistinct, permitted public activity in a constant state of evolution and rule making ensures that the urban sphere retains its energy and vitality.

Desire Lines are not Sight Lines, understood as important views of framed elements in a city or towards a distant landmark, natural or man-made. However, in automotive travel (when one is acting as the driver) they are one and the same; in pedestrian travel (this includes everyone) Desire Lines and Sight Lines may be unrelated - the path itself may be blind, it could be a ninety-degree bend, a whiplash curve, a steep drop (stair, ramp etc), broken etc.

\section{Urban tactics}

Walking was seen by Michel de Certeau as quite a powerful and personal manner in which to exist in the modern world. He explored the meaning of walking as a form of resistance from the instrumental spaces surrounding the citizen, as expressed by Habermas, in the modern city. In The Practice of Everyday Life, de Certeau speaks of 'La Perruque,' (the wig) a 'diversionary practice,' that he found to be a strong tactic of for instance, employees doing non-billable personal tasks on office time without being easily tracked [8, p. 24-5] such an attitude is reflective in walking itself, it is largely invisible on maps and from the view of a moving SOV (single occupancy vehicle) it looks ridiculously inefficient, but it does manage to be a form of circulation that eludes easy mapping and is very complex as compared to motorized travel.

A compelling psychological reason to improve the walkability of our urban cores in North America is to provide avenues for the pedestrian's need to find a shorter route that also contains elements of aesthetic contemplation and slowness. This idea is explored along the notion of desire lines, or 'Les chemins du désir,' a term coined by the French Philosopher Gaston Bachelard, in The Poetics of Space, who used it to relate to the beautiful instance of making pathways that are instinctive, habitual, that work on an emotional level in direct opposition to moving in lines inscribed onto the city that operate as (often rather mindless) offsets from property lines. These lines are imagined as well as realized. Compare this with the shared experience of drifting that occurs in a vehicle - one tends to lose track of the immediate, the present moment when on a long highway, especially if you are the driver.

Urban Filaments may be one vital way to increase the public way in the urban core and rapidly-urbanized areas where games of trade of use for the shod and the 4-wheeled are stalled at provincial/state levels 'highways,' that are used locally as 'street.' Difficulty also arises due to the separation of public and private construction timeframes from private property development cycles. Recognizing the difficulty of owners willingly parting with valuable groundlevel or otherwise, a fraction of their real estate for public use, there needs to be a discussion as to how to increase, annually, or by some measure, additional publicly-accessible walking space that promotes the growing local and national health concerns of the day; namely: health related to lifestyle related to 
obesity/type 2 diabetes. The growing body of research showing that a lack of walkable, desirable spaces, destinations, and variety of experiences tend to produce undesirable results in public health samples. This added to the problems of historic zoning by use and separation of residential from all other uses, is a large problem that needs addressing with the research/practice umbrella under connections.

One may wonder if this is one of the ways to get the attention of the private section to emerge as an active participant of publicly usable space for the greater good? Most work undertaken to address deficits of public amenity in the greater, physical public realm is challenged by this knee-jerk reaction by the private sector. Of course, not all small and large private enterprises have this reluctance to engage the public. There are some notable public figures who do aspire to make a difference in the public sphere; leaders of organizations from Turner Enterprises, Virgin Atlantic, Apple Computers, etc. have all managed to articulate a clear public vision for adding to the public good while maintaining success in daily business affairs.

Yet the question remains, why hasn't there been a large improvement in public development of Desire Lines? It might be a case of a lack of awareness of design, and possibly organizational structures that struggle with in-house communication. It does still pose a significant challenge to unravel the lines of communication between silo'd departments within one organization. These challenges have to be worked out from within and then the discussion between the city and the property owner can occur when all parties are ready.

The proportion of the city budget targeted to walkability and pedestrian innovations have to be compared to other expenditures. It would be worthwhile to see if there is a connection between desirability and urban health with a city pedestrian budget. Also, the benefits to be gained by promoting spaces that promote natural human tendencies - aka good design, seem obvious, but as Carl Myhill writes about such design decisions, the need for commercial success by looking for Desire Lines in many aspects of modern life, from product design to print, and in physical space are not always dealt with by companies or government. 'Desire Lines showing natural human purpose relating to a design are not so hard to see yet few companies focus on them...' [9]. There has to be more work done to raise awareness of how design thinking may offer many improvements to company bottom lines as well as added health benefits to a community or private site.

This pressing need to communicate the value of Desire Lines in public space, and good design in general, must be met with engaging research study in order to promote key decision making. Different scales of undertaking will offer a maximum range of opportunity; quick turnaround project success will be met at the very small, local level, and at the other end with large organizations and government, with strategic, long-term projects.

\section{Test cases}

Public/private partnerships should be initiated as test cases in the dense existing areas of pedestrian activity. If proven to be successful in generating more 
satisfaction by pedestrians, then eventually more connected paths would generate a network of local veins overlaid onto a fragment of the map of superblocks. Slowly, this expands the network of walking routes through the city by using density to create paradoxically more space for public movement. If no collaboration and design occur we are left with compromised spaces of the public sphere (see image above) that could have been an intermeshing of public and private spaces to better effect.

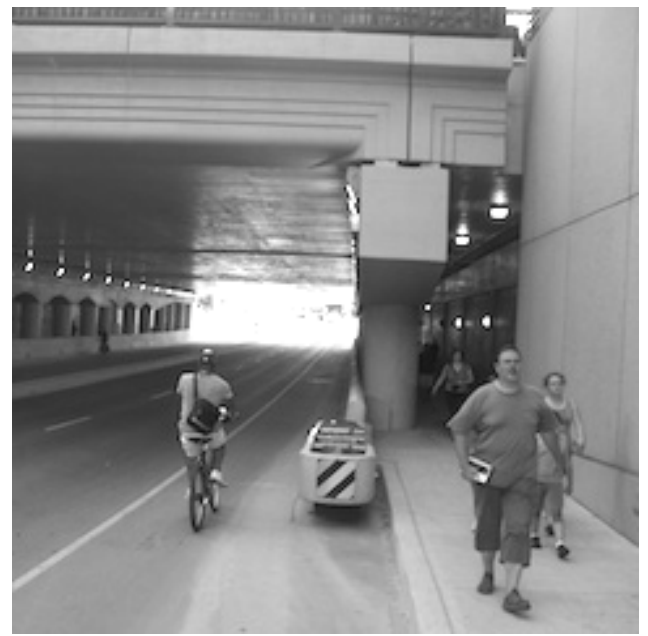

Figure 3: Serviceable yet not memorable poetically. Sidewalk narrowness.

Architects and designers should interconnect their buildings with access for walkers to pass through and into the spaces beyond the main foyers and mezzanines in a more organic fashion than what tends to be the case in many new projects. As a general rule, overall architectural form, surface materiality, and structural innovation lead most architectural strategies of design - pedestrian innovations and Desire Lines (+connections with other adjacent spaces) are not vanguard concerns in the projects highlighted in professional journals. Often the dominant goals have been a slavish adoption of LEED standards that ironically result in a platinum-level new project that has no access to the site by pedestrian, rapid transit, or cyclist route-it might even be in a new subdivision devoid of any infrastructure. This is an extreme example of looking inward at a site, but it underlines the importance of different property owners/sites to work together to interconnect potential linkages in the form of urban filaments. Should cities mandate for more porous urban space? Definitely. If there is a continuous strain on congested roadways and parking challenges nearby. It is one of the only ways to increase pedestrian (public) space.

The city plan, constantly evolving, can anticipate and leverage new construction and renovation work to embrace Urban Filaments/Desire Lines through various strategies and tactics. Borrowing from the many successful implementations of public art and historic restoration subsidies, to name a few, 
the system of creating dedicated new passages through public/private spaces could adopt the precedents to build test cases.

Another innovative system of walkways, perhaps aboveground, could borrow on the runaway success (for the city) of the Toronto PATH system network (see figure 1), which began as a city-funded initiative to connect new development into the existing underground (commercial) city, is now not even mandated, yet developers continue to connect to the infrastructure below grade because of pressure from tenant and buyer demand. Of course, new elevated systems have to be carefully studied and applied in actual sites, as the experiments in the last fifty years of above-ground walkways, in cities such as Calgary and Cincinnati, to name two, needs innovative solutions and new ideas to be carried forward so that the spaces don't become disconnected airlocks between offices and hotels.

It is worth commenting on some exceptions to the rule where pedestrian spaces have thrived in North America; these are examples of innovative spaces that were tactically saved. One of the oldest public Urban Filaments in North America is the Rideau Canal; like many significant urban public spaces in Canada, it was repurposed. It took 140 years from construction of the canal to it being saved from its being proposed to having been turned into a new expressway (!) into the current beautiful $7.2 \mathrm{~km}$ public seasonal skating route in Ottawa, Canada. Similar to this type of public space is the Seawall in Vancouver, British Columbia; it was a relic of military space given over to public and recreational use by upper levels of government. Today, it defines the city's experience with the water and with development.

The more recent public opening of the Highline pedestrian park, an abandoned elevated train track located on the west side of Manhattan, was given a new lease on life as an urban park, after it was deemed too costly to remove the metal offshore. Such examples demonstrate the power of public use of Urban Filaments in many situations where there were challenges to rework these pedestrian spaces as highways or be subdivided as private lots for developments. That they endure, are of a significant scale, and have become icons of public space is a testament to the creative will of local government and community action in redeveloping space for public pedestrian/active transportation (including cycling and skating, etc.) use.

In a recent politically-sensitive re-election, the mayor of Vancouver, B.C. decided to push through a quick roll out of an integrated bicycle lane network in the downtown with dedicated and painted laneways for cyclists. This was, in many respects a risky move, as it was deployed quickly without the usual long approval process-leaving many locals feeling alienated from the decision making process. He was reelected. However, since it now exists, it speaks to the fundamental difficulty of extracting space from the given area of road/street and sidewalks in the city. What would probably have taken years and been weakened, has, remarkably occurred in a relatively short time.

These examples of urban filament ribbons, predominantly in the public eye, along edges and distinguished from automotive travel are rich in future ideas for urban filaments given that many tap into adjacent buildings, large infrastructure in the form of under and overpasses, and merge into sidewalks, stairs and ramps, 
and, more often with accessible elevators and lifts. We will be seeing more examples of stitching together the public and private spaces of the city as things become denser and the population increases, looking for porous space to find those elusive quiet and calm spaces of retreat away from the main (automotive and transport-heavy) routes.

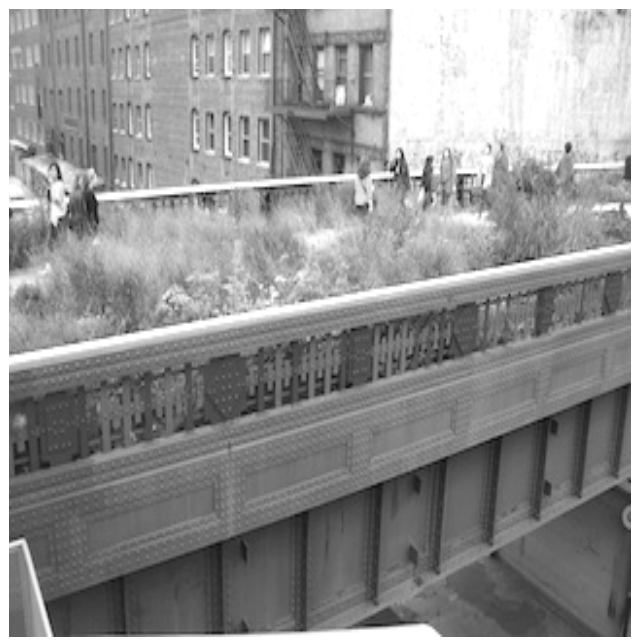

Figure 4: Accidentally found space-the NY Highline public park/promenade.

Future research will stimulate the test cases for opportunities to develop the Urban Filaments/Desire lines. For example, one study would be to analyze the relationship between the overall area allocated to underground, or otherwise, of parking spots for new construction (residential and commercial). The formula, if it has changed because of new standards in planning guidelines for density and proximity to rapid transit - this might mean that the 'surplus' area could be reallocated to pedestrian passageways and spaces to be determined in the early phases of the project, as compared to a tactical approach, that seeks out unused or underutilized, marginal spaces to connect public ways in/along public/private properties that are fully (privately) occupied with tenants/owners.

\section{Conclusion}

Urban Filaments are the realization of Desire Lines in the North American city. Urban Filaments are the physical manifestation of Desire Lines. The (tentative) steps to achieving new examples of Urban Filaments depend on the context in which the original Desire Lines have been drawn in a community.

If we believe cities are both destinations and events, we will need to revisit the staid pattern of street face design, and work collectively to open up the blockade of building properties that make up the bulk of the downtown experience. Otherwise, with automobile ownership growing (both in real 
numbers of vehicles desired and in the actual supersize of the vehicles) the pedestrian experience will continue to be turned into a relic species, cautioning whose only chance of survival is in enclosed private shopping and entertainment venues. This is a term used by Stephen Meyer who categorized human-focused spaces and all creatures that thrive in such a space as Weedy species, with relics being those who can only continue to exist in containment-as curiosities because they are strongly affected by the human hand in the environment (or in the case of pedestrians, the needs of the automobile over the historic pedestrian-centered communities and urban forms) [7, pp. 9-14].

Fraught with no other space to grow as it becomes more popular of an option - one cannot foresee city streets dwindling to only a single lane any time soon, so it isn't really always in our interest to compete with the road traffic engineers ideas of good design, concerning discussions of a one-sided conversation of peak hour efficiencies and flows of traffic dealing with vehicles and not pedestrian issues. These two competing ideas of what defines a street are really about cars versus people (walking). It requires real creativity to solve these large questions about how do we continue to grow.

Fundamentally these flows of circulation (not traffic, thank you) work differently, in terms of scale, experience, and predictability. Health research has shown growing proof that a steady diet of auto use results in obesity, a rise in type 2 diabetes, and overall increased strains on the health systems of a large population. Couple this with an aging population disconnected from multiple short walking/cycling trips in the day and we have a real need to invest in new tactics to work with the existing fabric of the city to explore vibrant walkable spaces and provide the urban sojourner with real choices in their destinations with the realization of Urban Filaments/Desire Lines.

\section{References}

[1] Bachelard, Gaston, Translated by Jolas, Maria, The Poetics of Space, Beacon Press: Boston, Mass., 1994.

[2] Barlow Rogers, Elizabeth, Rebuilding Central Park: A Management and Restoration Plan, The MIT Press: Cambridge, Mass., 1987.

[3] Furman, A. Urban filaments: from passageways of leisure-oriented space to emergent urban form, Brebbia C. A., Hernandez, S., Tiezzi, E. eds. The Sustainable City VI: Urban Regeneration and Sustainability. London, WIT Transactions on Ecology and the Environment, Vol. 129, WIT Press. pp. 265-274, 2010.

[4] Gopnik, Adam, Winter: five windows on the season, House of Anansi Press Inc.: Toronto, ON., 2011.

[5] Jacobs, Jane, The Death and Life of Great American Cities, Vintage Books: New York, 1992 (1961).

[6] Merlin, Coverley, Psychogeography, Pocket Essentials: Harpenden, Herts, 2010.

[7] Meyer, M. Stephen, The End of the Wild, Boston Review: Somerville, Mass., 2006. 
[8] Michel de Certeau, translated by Rendall, Steven F., The Practice of Everyday Life, University of California Press: Berkeley, Calif., 1984, (1997).

[9] Myhill, Carl, Commercial Success by Looking for Desire Lines:, in Masoodian, M., Jones, S., Rogers, B., eds. 6th Asia Pacific ComputerHuman Interaction Conference (APCHI), Rotorua, New Zealand, June/July. 2004. Retrieved from: http://www.litsl.com/personal/publications.html.

[10] Sheller, Mimi, and Urry, John, The City and the Car, in The International Journal or Urban and Regional Research Volume 24.4 December 2000. pp: 737-757. Blackwell Publishers Ltd.

[11] Wood, Denis, The Power of Maps, The Guildford Press: New York, N.Y., 1992. 